\title{
Elementos del aprendizaje cooperativo para la convivencia escolar
}

\section{Elements of cooperative learning for school coexistence}

DOI: $10.46932 / \mathrm{sfjdv2n5-090}$

Received in: Oct 1st, 2021

Accepted in: Dec 30th, 2021

\author{
Fabián Jesús Avendaño- Bolaño \\ Licenciado en Educación Básica con énfasis en Educación Física, Recreación y Deporte. \\ Universidad de Pamplona \\ Maestrando en Educación de la Universidad de Pamplona. \\ Docente de la Institución Educativa Distrital 20 de octubre. \\ Correo electrónico: fabian.avendano@unipamplona.edu.co

\section{Matilde Bolaño-Garcia} \\ Ph.D. En educación. \\ Doctorado en Gestión de la tecnología y la innovación. \\ Docente e investigadora de educación superior. \\ Correo electrónico: Matilde.bolano@gmail.com
}

\section{RESUMEN}

El aprendizaje cooperativo con el pasar de los años se ha convertido en una excelente metodología que aporta significativamente en la formación de los estudiantes, desde esta perspectiva se propuso, identificar los elementos del aprendizaje cooperativo según la teoría de Johnson \& Johnson, para la convivencia escolar en los estudiantes de $7^{\circ}$ la Institución Educativa Distrital 20 de octubre perteneciente a la comuna 1 del Distrito Turístico Cultural e Histórico de Santa Marta- Colombia. Además, posee un enfoque metodológico cualitativo a través de un diseño de investigación acción participativa, con una población estudiantil, en donde los resultados mostraron que este posee múltiples ventajas para aprender académicamente, convivencial y socialmente. Los resultados obtenidos permitieron ratificar que los elementos del aprendizaje cooperativo según la teoría de Johnson \& Johnson, contribuyen en el desarrollo de las distintas actividades grupales, con el fin, de adquirí responsabilidades, compromiso y habilidades logrando así mejorar las relaciones interpersonales, académicas y convivenciales.

Palabras clave: aprendizaje, cooperativo, convivência, trabajo grupal, formación, elementos.

\begin{abstract}
Cooperative learning over the years has become an excellent methodology that contributes significantly to the training of students, from this perspective it was proposed to identify the elements of cooperative learning according to the Johnson \& Johnson theory, for school coexistence in the 7th grade students, the District Educational Institution October 20 belonging to commune 1 of the Cultural and Historical Tourist District of Santa Marta- Colombia. In addition, it has a qualitative methodological approach through a participatory action research design, with a student population, where the results showed that it has multiple advantages to learn academically, convivially and socially. The results obtained allowed to confirm that the elements of cooperative learning according to the Johnson \& Johnson theory, contribute to the development of the different group activities, in order to acquire responsibilities, commitment and skills, thus improving interpersonal, academic and convivial relationships.
\end{abstract}


Keywords: learning, cooperative, coexistence, team work, training, personal relationships.

\section{INTRODUCCIÓN}

Los seres humanos, conciben como la principal fuente de riqueza y de patrimonio más importante durante el proceso educativo, como lo es el conocimiento y la información, los cuales son la base para la formación y desarrollo de la humanidad. Puesto que, aprender es la capacidad que poseen para adquirir conocimientos, pero para ello se debe descubrir todo lo que se puede y no se puede hacer, con el fin de lograr resultados favorables en la formación. Por otro lado, la cooperación es el trabajo en unidad, donde el propósito es lograr un objetivo común y de esta manera beneficiarse a uno mismo y beneficiar a los demás.

Johnson, Johnson y Holubec (1999), resaltan que, el aprendizaje cooperativo (AC) es un método de enseñanza basado en el trabajo en grupos pequeños y diversos, en los que los estudiantes unen sus fuerzas y comparten recursos para potenciar su aprendizaje y el de los demás miembros del grupo. Es decir, la cooperación entre individuos es llevar a cabo actividades conjuntas para lograr resultados beneficiosos para todos los integrantes del equipo y así obtener resultados favorables.

Pero, para obtener estos resultados y aplicar adecuadamente el AC, es importante resaltar, que la educación cada día posee múltiples permutaciones, en cuanto a metodología, estrategias, contenidos, entre otros, requiere que el docente este presto a las transformaciones educativas y de esta manera formar a las futuras generaciones, para que sean capaces de afrontar los cambios que favorecen su proceso educativo y su desenvolvimiento en la sociedad, puesto que, las relaciones interpersonales entre todos es fundamental, porque ayuda a tener una armonía en cada uno de los espacios que se habitan.

Cabe resaltar que, para que la cooperación se desarrolle adecuadamente, es fundamental aplicar los elementos básicos en cada una de las clases los son: interdependencia positiva, responsabilidad personal, manejo del grupo, habilidades sociales, lo que significa que el uso del AC requiere disciplina por parte de maestros y estudiantes, debido a que, los elementos básicos no son solo las características de un buen grupo de estudio, sino que también representan una disciplina que debe aplicarse estrictamente para producir condiciones propicias para una acción cooperativa eficaz.

En este orden de ideas, se resalta uno de los elementos fundamentales que posee el AC como lo es las habilidades sociales, puesto que, las interacciones sociales son muy importante en el proceso de formación establecidas durante el proceso de enseñanza-aprendizaje de los educandos, jugando un papel importante en la construcción del conocimiento y en el logro de resultados que se esperan obtener de manera significativa en el aprendizaje. Por tanto, no se debe 
olvidar que, el campo en el que se construye un organismo vivo en cuanto a la estructura que constituye las relaciones sociales, culturales, psicológicas, es en la escuela y en el hogar de cada uno de ellos, permitiendo que se definan: las características propias de los individuos, como lo es la capacidad de actuar, pesar, relacionarse y de expresar las ideas u opiniones.

Vázquez y Kustala (2018), expresan que, los docentes siempre deben apoyar, motivar, acompañar y estar constantemente en la formación de los estudiantes, para así evitar la deserción o los fracasos escolar. En otras palabras, la labor del docente es muy importante en la escuela, porque contribuye en la formación de los educandos durante su proceso de crecimiento, asimismo, educar implica en su totalidad abarcar el sistema educativo, llevar a cabo los modelos pedagógicos, técnicas didácticas, indagación y utilización de estrategias, que favorezcan un adecuado aprendizaje y acompañamiento constante.

Por otra parte, la sociedad hoy en día presenta numerosas problemáticas (violencia, maltrato, hurtos, entre otros) donde los protagonistas son algunos jóvenes, puesto que, realizan este tipo de actos inadecuado, muchas veces los hacen por la necesidad de tener dinero, de lo que ven en su contexto o simplemente gusto y este es otro de los motivos por lo que dejan de asistir a la escuela o es su defecto acuden y cometen estas clases de cosas dentro de ellas, haciendo que la convivencia escolar y las relaciones interpersonales se vea afectada.

Después de un exhaustivo estudio sobre las distintas problemáticas que presenta los estudiante hoy en día y las diversas situaciones que ocurren dentro de la institución, las cuales afectan la convivencia escolar y el rendimiento académico, se encontró que la aplicabilidad de la teoría de Johnson \& Johnson y los diferentes elementos que se resaltan en esta teoría, por esta razón, se propuso identificar los elementos del AC según la teoría de Johnson \& Johnson, para la convivencia escolar en los estudiantes de $7^{\circ}$ la Institución Educativa Distrital (I.E.D) 20 de octubre perteneciente a la comuna 1 del Distrito Turístico Cultural e Histórico (DTCH) de Santa Marta- Colombia.

\section{TEORÍA DEL APRENDIZAJE COOPERATIVO}

El AC busca fortalecer la membresía individual, lo que significa que los estudiantes aprendan a desenvolverse ante cualquier situación y así puedan desempeñarse como individuos ante la sociedad. Es decir, el AC incluye agrupar a un número determinado de personas para lograr un objetivo común, y que cada uno asume un papel básico en el trabajo grupal en el aula, esto asegura la realización del objetivo, que es imposible de alcanzar de manera individual.

Según Johnson y Johnson (1987), los grupos de trabajos se ocupa de la interdependencia activa entre los miembros del equipo. La estructura de metas hace que los estudiantes se interesen no solo en sus propios esfuerzos y desempeño, sino también en el desempeño de los demás. Por eso existe una estructura de metas: el número de asignaturas asignadas a cada alumno tiene una clara responsabilidad personal, 
además, brinda al grupo y a sus integrantes información sobre el progreso de los demás para que sepan quién necesita ayuda, todos los miembros del equipo comparten el liderazgo y las responsabilidades de aprendizaje, y el objetivo final es hacer que los componentes de aprendizaje estén disponibles para todos.

En este orden ideas Velázquez et al. (2014) citan a Johnson \& Johnson, (1999), en donde resaltan que el enfoque conceptual del AC implica la presencia en el proceso de trabajo en equipo, de cinco características esenciales: (1) la interdependencia positiva de metas, puede integrarse con otras, recursos como roles o identidades, (2) promueven la interacción cara a cara, (3) la responsabilidad personal, lo que implica que nadie puede aplicar una actitud pasiva, esconderse detrás del trabajo de otros, (4) trabajar entre individuos y grupos pequeños, y (5 ) la construcción del equipo o el proceso en el que el grupo identifica las conductas que se manifiestan durante la ejecución de la tarea, identificando que contribuyeron a la finalización de la tarea y fueron perjudiciales, para reforzar la primera conducta y sugiriendo alternativas a las posteriores.

Cabe señalar que, esto permite a los estudiantes desarrollar un aprendizaje significativo para explorar su potencial personal, como la retención a largo plazo del conocimiento aprendido, una visión general de lo aprendido y la contextualización del aprendizaje. En otras palabras, esta es una forma de lograr la calidad educativa requerida por toda la organización escolar, pero lograr este objetivo requiere del maestros, coordinadores y demás personas que estén dispuestos a trabajar y aprender juntos para reconstruir nuevas formas y comportamientos escolares.

El AC posee unos elementos que son primordiales para el desarrollo de actividades y la implementación de esta metodología con los estudiantes, las cuales son mencionadas por Arbildo, (2018), en donde citan a Johnson y Johnson (1999.) estas son:

Tabla 1. Elementos del aprendizaje cooperativo Johnson y Johnson (1999)

Elementos Fundamentales del AC de Johnson y Johnson (1999)

\begin{tabular}{|c|c|}
\hline \multicolumn{2}{|r|}{ Elementos Fundamentales del AC de Johnson y Johnson (1999) } \\
\hline $\begin{array}{l}\text { Interdependencia } \\
\text { positiva: }\end{array}$ & $\begin{array}{l}\text { Esta contiene la adquisición de las metas personales y la obtención del producto } \\
\text { final, es decir, el trabajo a ejecutar depende del desarrollo de todos. }\end{array}$ \\
\hline $\begin{array}{l}\text { Responsabilidad } \\
\text { individual: }\end{array}$ & $\begin{array}{l}\text { Dividir el trabajo a desarrollar en las distintas partes de los participantes, es decir, } \\
\text { cada persona es responsable de qué asignar. Responsabilidades individuales en la } \\
\text { evaluación del rendimiento de cada estudiante, comunicar los resultados a grupos } \\
\text { e individuos e identificar a aquellos que necesitan más ayuda, apoyo y aliento } \\
\text { para completar las tareas asignadas a ellos. }\end{array}$ \\
\hline Procesamiento grupal: & $\begin{array}{l}\text { Esto se refiere a las necesidades actuales del grupo. Se deben establecer } \\
\text { parámetros o mecanismos democráticos ante cualquier debate para tomar } \\
\text { decisiones consensuadas entre todos los miembros. Por otro lado, es fundamental } \\
\text { que se proceda después del trabajo. Autoevaluación, puede abarcar aspectos } \\
\text { cognitivos o aspectos relacionados con las actitudes. }\end{array}$ \\
\hline Habilidades sociales: & $\begin{array}{l}\text { A lo largo del trabajo en grupo es importante considerar, las capacidades sociales } \\
\text { de convivencia y conocimiento como por ejemplo respetar los turnos de palabra, } \\
\text { compartir el liderazgo, encargarse correctamente los conflictos, criticar opiniones } \\
\text { y no personas, ayudarse etcétera. Estas capacidades se tienen que instruir al } \\
\text { mismo grado que otros contenidos académicos clásicos. }\end{array}$ \\
\hline
\end{tabular}

Fuente: propia, teniendo en cuenta lo expuesto por Arbildo, 2018, (p.46) 


\section{APRENDIZAJE COOPERATIVO EN LA EDUCACIÓN FÍSICA}

La educación física es una disciplina que, por su propia naturaleza, proporciona un entorno agradable, en donde los estudiantes fomenten la comunicación y la interacción social (Lang, Koegel, Ashbauhg, Regester, Ence y Smith, 2010), es decir esta área promueve las relaciones, la unión, la cooperación desde las distintas actividades y en la práctica de los deportes que se desarrollan en esta asignatura de una manera armónica tanto individual como grupal.

Es por esto que, la aplicabilidad del AC y sus elementos en el área de educación física aporta significativamente en la formación de los educandos puesto que ayuda en el desarrollo metodológico de los distintos deportes, asimismo lo resalta Solana (2007), el AC en la educación física es motivador, promueve la cohesión social, apoya el desarrollo cognitivo, es práctico y facilita la organización del aula.

De igual forma lo señala Velázquez (2012), en donde expresa que la aparición del AC en la educación física comenzó con la teoría de la cooperación, la competencia y su aplicación en los distintos espacios y ambientes (Deutsch, 1949), es decir que, con esta metodología se busca obtener una regulación en el conflicto y apuntar por una educación para la paz. Pues esta dinámica por ser grupal exige a los estudiantes la interacción con personas cuya postura ante la realidad es diferente, lo cual ayuda a crear conciencia en cuanto al respetar la diversidad.

Por otra parte, el juego está basado especialmente en unos de los elementos del AC, el cual hace referencia a la interdependencia positiva, en el que busca como producto un trabajo práctico en la creación e implementación de programas de juego cooperativo, esta idea es sustentada por (Provost y Villeneuve, 1980); Orlick, 1978), quienes precisan que, además, la aplicación de la teoría de Deutsch (1949) en el campo de la educación condujo a la teoría de la interdependencia social (Johnson y Johnson, 1989) y al AC en sí.

En resumidas, el AC consiste en trabajar en equipo, buscando la corresponsabilidad de cada educando por adquirir y demostrar sus propios aprendizajes, pero también es muy importante conocer los conocimientos de los demás miembros, debido a que, la cooperación promueve el aumento a la autoestima, confianza, motivación, rendimiento y una actitud positiva hacia la participación y el autocontrol de todos.

Entendida como la base de relaciones interpersonales que se dan entre todos los miembros de la comunidad educativa, eso es la convivencia escolar, además en este concepto se configuran procesos de comunicación, sentimientos, valores, actitudes, roles, status y poder (Ortega, 1997). El autor anteriormente señalado afirma que, cada día está en constantes cambios y sus comportamientos son demostrados con mucha facilidad y es aquí en donde la convivencia, lo académico están enlazados, porque al implementar estrategias innovadoras se busca que ellos mantengan un amplio grado de concentración en lo académico centrándose en aprender a trabajar en equipo. 


\section{METODOLOGÍA}

Este estudio estuvo basado en la teoría de Johnson y Johnson, regido bajo un enfoque cualitativo, con un método de investigación - acción (IA), a estudiantes de séptimo grado, esta es una investigación de carácter descriptivo que permitió analizar la información compilada para luego hacer la respectiva interpretación y descripción del fenómeno estudiado, por su partes, las principales herramientas utilizadas para la recolección de datos, independientemente del método o modelo de investigación aplicado, son: observación directa, recopilación o investigación documental, entrevista, cuestionario, encuesta, para así realizar un análisis a los resultados obtenidos.

En este estudio, la población perteneció a la I.E.D. 20 de Octubre sede Monterrey de la ciudad de Santa Marta, estuvo conformada a nivel general por treinta y cinco (35), estudiantes, de los cuales diecisietes (17) son niños y dieciocho (18) niñas pertenecientes a una institución, y se encuentran cursando el nivel la educación básica secundaria, con edades comprendidas entre los 12 y 13 años, procedentes de diversos sectores tanto rural como urbano.

Tabla 1. Población general y muestra del grado séptimo

Población general de estudiantes en el grado Informantes claves en el grado séptimo séptimo

\begin{tabular}{|l|l|l|l|}
\hline Sexo & Cantidad & Sexo & Cantidad \\
\hline Niñas & 17 & Niñas & 4 \\
\hline Niños & 18 & Niños & 6 \\
\hline Total & 35 & Total & 10 \\
\hline
\end{tabular}

Fuente: Elaboración propia

Agregando que, los autores de Hernández, Fernández y Baptista (2006) enfatizan que la ruta de investigación es IA y el diseño del método es cualitativo y descriptivo, lo cual es muy importante. Ellos se enfatizan que la investigación descriptiva tiene como objetivo establecer normas para los atributos, características y perfiles. de individuos, grupos, comunidades u otros eventos importantes que necesitan ser analizados.

Además, las fases permiten concretar los elementos necesarios, para compilar e interpretar información relacionada a la problemática en estudio. A través de las fases de la investigación, se puede ir desarrollando el plan de acción teniendo en cuenta los resultados conseguidos de la interpretación de la información recolectada. En esta investigación se desarrollaron cuatros fases principalmente, fase (1) diagnóstico, fases (2) construcción, fase (3) ejecución y observación, fase (4) reflexión e interpretación

\section{RESULTADOS}

Como resultado en esta investigación, se tiene que con el AC y con los distintos elementos que este posee, se encontró que los estudiantes en el aula tienen más confianza, porque su participación es 
activa, y ellos constantemente responden y prestan atención a todo lo que se les explica. Además, lograron identificarse a sí mismos y a los demás, es decir, comprender sus propias habilidades, destrezas, etc., y así se han sentido parte del equipo y de esta manera realizan su trabajo desarrollando sus funciones en el equipo adecuadamente, tal como se muestra en la siguiente tabla.

Tabla 2 Resultados

\begin{tabular}{|c|c|c|c|c|c|c|c|}
\hline $\begin{array}{c}\text { Categorí } \\
\text { as }\end{array}$ & $\begin{array}{c}\text { Sub } \\
\text { Categorí } \\
\text { as } \\
\end{array}$ & $\begin{array}{c}\text { Participante } \\
1\end{array}$ & $\begin{array}{c}\text { Participante } \\
2\end{array}$ & $\begin{array}{c}\text { Participante } \\
\mathbf{3}\end{array}$ & $\begin{array}{c}\text { Participante } \\
4\end{array}$ & $\begin{array}{c}\text { Participante } \\
5\end{array}$ & $\begin{array}{c}\text { Participante } \\
6\end{array}$ \\
\hline \multirow{3}{*}{ 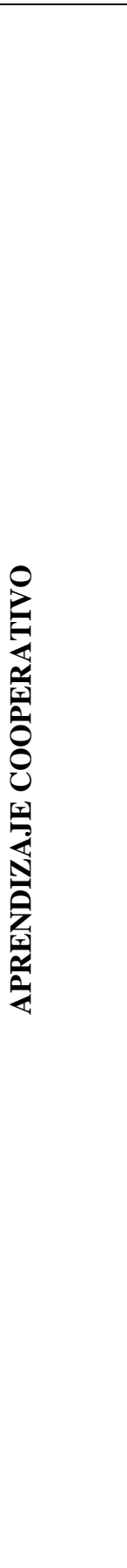 } & $\begin{array}{l}\text { Interdep } \\
\text { endencia } \\
\text { positiva. }\end{array}$ & $\begin{array}{l}\text { En las clases, } \\
\text { tuve una } \\
\text { participación } \\
\text { muy buena, } \\
\text { realicé todas } \\
\text { las } \\
\text { actividades y } \\
\text { me relacioné } \\
\text { con los } \\
\text { demás } \\
\text { compañeros. }\end{array}$ & $\begin{array}{l}\text { En las clases, } \\
\text { participe } \\
\text { excelenteme } \\
\text { nte, preste } \\
\text { atención a } \\
\text { las } \\
\text { indicaciones, } \\
\text { realicé los } \\
\text { ejercicios, } \\
\text { hice las } \\
\text { actividades. }\end{array}$ & $\begin{array}{l}\text { Mi } \\
\text { participación } \\
\text { en las clases, } \\
\text { fueron muy } \\
\text { buenas, hice } \\
\text { todo lo } \\
\text { asignado, } \\
\text { seguí las } \\
\text { indicaciones } \\
\text { y trabajé con } \\
\text { mis } \\
\text { compañeros } \\
\text { de una } \\
\text { manera muy } \\
\text { tranquila. }\end{array}$ & $\begin{array}{l}\text { En las clases } \\
\text { participe muy } \\
\text { activo, realicé } \\
\text { todo, las } \\
\text { actividades, } \\
\text { además trabaje } \\
\text { con mis } \\
\text { compañeros } \\
\text { sin ningún } \\
\text { inconveniente. }\end{array}$ & $\begin{array}{l}\text { Tuve una } \\
\text { participación } \\
\text { activa, } \\
\text { desarrollé } \\
\text { todas las } \\
\text { actividades, } \\
\text { aprendí, } \\
\text { divertí y } \\
\text { compartí con } \\
\text { mis } \\
\text { compañeros, } \\
\text { hice todo y } \\
\text { preste } \\
\text { atención al } \\
\text { docente. }\end{array}$ & $\begin{array}{l}\text { En las clases } \\
\text { participe } \\
\text { excelenteme } \\
\text { nte, hice las } \\
\text { actividades, } \\
\text { además, me } \\
\text { divertí y } \\
\text { aprendí } \\
\text { mucho. }\end{array}$ \\
\hline & $\begin{array}{c}\text { Respons } \\
\text { abilidad } \\
\text { individu } \\
\text { al. }\end{array}$ & $\begin{array}{l}\text { Realice todas } \\
\text { las } \\
\text { didácticas, } \\
\text { además } \\
\text { realice mis } \\
\text { tareas, } \\
\text { trabajos u } \\
\text { actividades. }\end{array}$ & $\begin{array}{l}\text { Fui muy } \\
\text { responsable } \\
\text { con todas las } \\
\text { tareas, } \\
\text { trabajos, } \\
\text { talleres u } \\
\text { actividades } \\
\text { que se me } \\
\text { asignaban en } \\
\text { las clases de } \\
\text { educación } \\
\text { física. }\end{array}$ & $\begin{array}{l}\text { Entregue } \\
\text { todas mis } \\
\text { tareas, } \\
\text { trabajos u } \\
\text { actividades, } \\
\text { además } \\
\text { realice todo } \\
\text { lo que el } \\
\text { profesor nos } \\
\text { colocaba } \\
\text { hacer en las } \\
\text { actividades } \\
\text { prácticas. }\end{array}$ & $\begin{array}{l}\text { Soy muy } \\
\text { responsable } \\
\text { entregue todas } \\
\text { mis } \\
\text { actividades, } \\
\text { tareas, trabajos } \\
\text { y talleres. }\end{array}$ & $\begin{array}{l}\text { Fui muy } \\
\text { responsable } \\
\text { en la entrega } \\
\text { de trabajos } \\
\text { asignados, } \\
\text { además } \\
\text { realicé los } \\
\text { ejercicios } \\
\text { practicos }\end{array}$ & $\begin{array}{l}\text { fui muy } \\
\text { responsable } \\
\text { en la entrega } \\
\text { de trabajos, } \\
\text { tareas, } \\
\text { talleres, } \\
\text { además } \\
\text { realicé muy } \\
\text { bien todos } \\
\text { los } \\
\text { ejercicios. }\end{array}$ \\
\hline & $\begin{array}{c}\text { Procesa } \\
\text { miento } \\
\text { grupal. }\end{array}$ & $\begin{array}{l}\text { La } \\
\text { asignación } \\
\text { de grupos } \\
\text { divertida, se } \\
\text { realizaban } \\
\text { actividades } \\
\text { para cambiar } \\
\text { integrantes, } \\
\text { aportábamos } \\
\text { ideas, } \\
\text { escuchamos, } \\
\text { dialogamos y } \\
\text { había unión, } \\
\text { participación } \\
\text { creatividad, } \\
\text { interacción } \\
\text { entre todos. }\end{array}$ & $\begin{array}{l}\text { Fue muy } \\
\text { divertido, la } \\
\text { unión, el } \\
\text { dialogo, } \\
\text { escucha, se } \\
\text { reflejaba, se } \\
\text { notaba la } \\
\text { creatividad, } \\
\text { participación } \\
\text { de todos, } \\
\text { puesto que, } \\
\text { cada uno } \\
\text { cumplía con } \\
\text { su rol. }\end{array}$ & $\begin{array}{l}\text { El } \\
\text { desempeño } \\
\text { excelente, } \\
\text { porque nos } \\
\text { escuchábam } \\
\text { os, } \\
\text { trabajamos } \\
\text { unidos, se } \\
\text { apreciaba las } \\
\text { habilidades, } \\
\text { capacidades } \\
\text { de los } \\
\text { compañeros, } \\
\text { respetando } \\
\text { las } \\
\text { opiniones. }\end{array}$ & $\begin{array}{l}\text { Durante las } \\
\text { clases, trabaje } \\
\text { adecuadament } \\
\text { e, había } \\
\text { escucha, } \\
\text { dialogo, unión, } \\
\text { comunicación, } \\
\text { se respetaba lo } \\
\text { que los demás } \\
\text { decía, había } \\
\text { liderazgo, } \\
\text { creatividad. }\end{array}$ & $\begin{array}{l}\text { Se trabajo en } \\
\text { grupo de } \\
\text { adecuadame } \\
\text { nte, las } \\
\text { actividades } \\
\text { asignadas } \\
\text { eran } \\
\text { diferentes } \\
\text { permitía que } \\
\text { en los grupos } \\
\text { apreciáramo } \\
\text { s las } \\
\text { opciones y } \\
\text { capacidades } \\
\text { del otro. }\end{array}$ & $\begin{array}{l}\text { Se trabajó en } \\
\text { grupo, } \\
\text { pudimos } \\
\text { relacionarno } \\
\text { s, dar los } \\
\text { aportes, } \\
\text { valorar el de } \\
\text { los demás, } \\
\text { además, el } \\
\text { líder estaba } \\
\text { encargado de } \\
\text { dirigir los } \\
\text { grupos y } \\
\text { entre todos } \\
\text { trabajamos. }\end{array}$ \\
\hline
\end{tabular}




\begin{tabular}{|c|c|c|c|c|c|c|c|}
\hline & $\begin{array}{c}\text { Habilida } \\
\text { des } \\
\text { sociales. }\end{array}$ & $\begin{array}{l}\text { Durante el } \\
\text { desarrollo las } \\
\text { de clases mi } \\
\text { desempeño } \\
\text { en los de } \\
\text { trabaje fue } \\
\text { muy buena, } \\
\text { logre } \\
\text { interactuar } \\
\text { positivament } \\
\text { e con los } \\
\text { integrantes. }\end{array}$ & $\begin{array}{l}\text { Tuve buena } \\
\text { relación con } \\
\text { los demás, } \\
\text { las } \\
\text { actividades } \\
\text { se realizaron } \\
\text { con orden y } \\
\text { dedicación, } \\
\text { haciendo } \\
\text { nuestras } \\
\text { funciones en } \\
\text { los roles } \\
\text { asignados. }\end{array}$ & $\begin{array}{l}\text { Se trabajó } \\
\text { excelenteme } \\
\text { nte, hubo } \\
\text { muchas } \\
\text { relaciones } \\
\text { interpersonal } \\
\text { es, } \\
\text { comunicació } \\
\text { n, respeto, } \\
\text { cada uno } \\
\text { realizó sus } \\
\text { funciones } \\
\text { según su rol. }\end{array}$ & $\begin{array}{l}\text { La interacción } \\
\text { social muy } \\
\text { buena, } \\
\text { realizamos las } \\
\text { actividades } \\
\text { cumpliendo } \\
\text { con los roles } \\
\text { correspondient } \\
\text { es en cada } \\
\text { trabajo. }\end{array}$ & $\begin{array}{l}\text { Los trabajos } \\
\text { realizados } \\
\text { permitieron } \\
\text { que nos } \\
\text { relacionáram } \\
\text { os y que } \\
\text { tuviéramos } \\
\text { buenas } \\
\text { relaciones } \\
\text { interpersonal } \\
\text { es. }\end{array}$ & $\begin{array}{l}\text { Tuve buena } \\
\text { relación } \\
\text { interpersonal } \\
\text { con los } \\
\text { demás, } \\
\text { dialogábamo } \\
\text { s, } \\
\text { conversábam } \\
\text { os y nos } \\
\text { respetábamo } \\
\text { s. }\end{array}$ \\
\hline \multirow{2}{*}{ 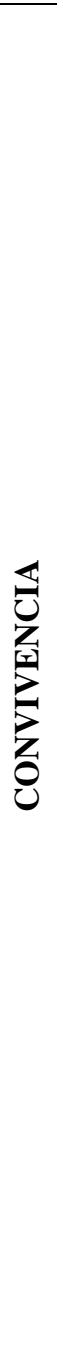 } & $\begin{array}{c}\text { Convive } \\
\text { ncia } \\
\text { escolar }\end{array}$ & $\begin{array}{l}\text { Durante el } \\
\text { desarrollo de } \\
\text { clases, la } \\
\text { convivencia } \\
\text { fue buena, } \\
\text { porque } \\
\text { respetamos } \\
\text { la palabra del } \\
\text { profesor y de } \\
\text { los } \\
\text { compañeros. }\end{array}$ & $\begin{array}{l}\text { En las clases } \\
\text { el } \\
\text { comportamie } \\
\text { nto muy } \\
\text { bueno, } \\
\text { respetábamo } \\
\text { s al docente y } \\
\text { a los demás, } \\
\text { no hubo } \\
\text { discusión ni } \\
\text { malos tratos } \\
\text { entre } \\
\text { nosotros. }\end{array}$ & $\begin{array}{l}\text { Las clases } \\
\text { fueron muy } \\
\text { tranquilas y } \\
\text { divertidas } \\
\text { todos } \\
\text { estábamos } \\
\text { centrados en } \\
\text { realizar las } \\
\text { actividades } \\
\text { asignadas, } \\
\text { ordenadame } \\
\text { nte y no se } \\
\text { presentó } \\
\text { ningún } \\
\text { inconvenient } \\
\text { e. }\end{array}$ & $\begin{array}{l}\text { La } \\
\text { convivencia } \\
\text { fue muy } \\
\text { buena, todos } \\
\text { estábamos } \\
\text { centrados en } \\
\text { trabajar y } \\
\text { realizar cada } \\
\text { una de las } \\
\text { actividades, } \\
\text { nos } \\
\text { respetamos y } \\
\text { convivimos en } \\
\text { paz. }\end{array}$ & $\begin{array}{l}\text { Todas las } \\
\text { clases } \\
\text { estuvieron } \\
\text { ordenas y } \\
\text { tranquilas, } \\
\text { trabajamos y } \\
\text { aportamos, } \\
\text { no nos llamó } \\
\text { la atención } \\
\text { en ningún } \\
\text { momento. }\end{array}$ & $\begin{array}{l}\text { Me sentí } \\
\text { muy bien, no } \\
\text { se presentó } \\
\text { ningún } \\
\text { inconvenient } \\
\text { e entre los } \\
\text { compañeros, } \\
\text { nos } \\
\text { centremos en } \\
\text { aprender. }\end{array}$ \\
\hline & $\begin{array}{l}\text { Clima } \\
\text { escolar }\end{array}$ & $\begin{array}{l}\text { Siempre } \\
\text { manejamos } \\
\text { el respeto, la } \\
\text { tolerancia y } \\
\text { el buen trato } \\
\text { con los } \\
\text { compañeros } \\
\text { trabajamos y } \\
\text { aportamos } \\
\text { buenas ideas } \\
\text { para tener un } \\
\text { buen trabajo. }\end{array}$ & $\begin{array}{l}\text { En las clases, } \\
\text { se notó el } \\
\text { respeto, la } \\
\text { tolerancia y } \\
\text { el buen trato } \\
\text { con los } \\
\text { demás y el } \\
\text { docente, } \\
\text { respetamos } \\
\text { las } \\
\text { opiniones, } \\
\text { las ideas y se } \\
\text { cumplió con } \\
\text { sus } \\
\text { obligaciones } \\
\text {. }\end{array}$ & $\begin{array}{l}\text { Durante las } \\
\text { clases } \\
\text { siempre } \\
\text { manejamos } \\
\text { el respeto } \\
\text { por el otor y } \\
\text { por uno } \\
\text { mismo, } \\
\text { además de } \\
\text { tolerarnos y } \\
\text { tratarnos } \\
\text { bien. }\end{array}$ & $\begin{array}{l}\text { En las clases se } \\
\text { vio el respeto, } \\
\text { la tolerancia y } \\
\text { el buen trato } \\
\text { entre nosotros } \\
\text { mismo y los } \\
\text { demás, esto } \\
\text { fue muy } \\
\text { importante } \\
\text { para que la } \\
\text { convivencia } \\
\text { fuera muy } \\
\text { buena y sin } \\
\text { ningún } \\
\text { contratiempo. }\end{array}$ & $\begin{array}{l}\text { Las clases } \\
\text { muy } \\
\text { tranquilas, } \\
\text { no se } \\
\text { presentó } \\
\text { ningún } \\
\text { inconvenient } \\
\text { e, siempre } \\
\text { hubo un } \\
\text { buen trato, } \\
\text { respeto y } \\
\text { tolerancia, } \\
\text { todo y } \\
\text { ordenado y } \\
\text { con un } \\
\text { excelente } \\
\text { comportamie } \\
\text { nto. }\end{array}$ & $\begin{array}{l}\text { Las clases } \\
\text { siempre se } \\
\text { vivió un } \\
\text { ambiente de } \\
\text { respeto, } \\
\text { tolerancia y } \\
\text { buen trato } \\
\text { entre } \\
\text { nosotros y el } \\
\text { docente, } \\
\text { trabajábamo } \\
\text { s } \\
\text { ordenadame } \\
\text { nte y con un } \\
\text { ambiente } \\
\text { ordenado. }\end{array}$ \\
\hline
\end{tabular}

Fuente: Elaboración propia

\section{CONCLUSIONES Y RECOMENDACIONES}

Se puede concluir que el AC es considerado actualmente uno de los recursos metodológicos fundamentales, porque desde los distintos elementos posee una efectividad en los logros sociales y académicos de los estudiantes en diferentes campos, niveles y entornos de aprendizaje, ofreciéndole a todos lectores diversas propuestas útiles que favorecen en el enriquecimiento estratégico y didáctico, además de un material de apoyo para todo los docentes, puesto que, brindará pautas necesarios para 
obtener un excelente y productivo trabajo en las aulas de clases desde las diversas asignaturas, porque se comprobará que el AC y sus elementos promueve y apunta al mejoramiento convivencial y académico de la juventud de hoy en día, demostrando su habilidades sociales, su desenvolvimiento en cada una de las competencias y en la construcción de conocimientos.

Asimismo, se logró analizar la incidencia del AC a través de la implantación y aplicación de los distintos elementos que este posee, desde el área de educación física, en donde se implementó el deporte del beisbol como instrumento del método pedagógico para mejorar la convivencia en estudiantes, porque por medio de este se pueden trabajar cooperativamente cumpliendo con el rol que se le asigna a cada integrante, es decir, cada uno se desenvolvió adecuadamente, además, cumpliendo con las normas, pautas y reglamentos que este posee, con un solo propósito de alcanzar las metas que se propongan como equipo y de esta manera resolver situaciones adversas que se presenten entre ellos mismo, logrando así espacios de armonía y paz.

Añádase que, es posible trabajar con los estudiantes los elementos del AC, en los cuales se visualiza una interdependencia plenamente activa, logran metas personales dentro del grupo para obtener resultados favorables, además, demuestran que los individuos entregan el trabajo de una manera oportuna, teniendo en cuenta un equipo continuo para responder y cumplir con todo lo asignado, para luego realizar autoevaluaciones, resaltar las funciones que desempeña cada persona, y finalmente, habilidades sociales para que todos puedan conectarse adecuadamente, respetar y observar los valores.

Además, el AC cuenta con la disponibilidad de actividades o estrategias, las cuales se reflejan y elaboran a través de la secuencia didácticas, la cual se enfoca en el proceso educativo y el aprendizaje de los estudiantes para lograr el resultado final, es decir, obtienen todo lo que hacen en la institución educativa. Asimismo, este proceso permite que se les asigne un rol para el desempeño de sus funciones y que tengan habilidades de liderazgo, lo que les ayuda a incrementar su sentido de responsabilidad y autoconfianza. Esto se visualiza en su trabajo y la evaluación aplicada a cada secuencia a través de la rúbrica de evaluación.

Igualmente, el AC y sus elementos ofrecen la oportunidad de poder trabajar, contenidos conceptuales, como aquellos temas transversales que son importantes y que aportan en la formación de los educandos de una manera íntegra, ganando así espacios con un ambiente de cooperativismo, que apunte a la vivencia de valores, el respeto por las diferencias individuales y grupales, la autonomía, la confianza, la motivación, interés y la participación, en donde los beneficiados será los estudiantes, porque se convertirán en seres críticos y reflexivos comprometidos con el cambio social.

Tendiendo en cuenta los resultados obtenidos en las diferentes sistematizaciones y las conclusiones mencionadas anteriormente se hace pertinente resaltar las siguientes recomendaciones: 
- Es importante trabajar dentro de las instituciones educativas todos los aspectos básicos del AC, los cuales se pueden incluirse en las evaluaciones, las habilidades y los roles de los niños. Esto se debe a la gran cantidad de información que se puede utilizar para investigar todos los aspectos.

- Con estas investigaciones se busca animar a futuros investigadores para que agreguen los resultados aquí obtenidos y compararlos con otras herramientas que permitan la recopilación de información adicional y así ver los cambios.

- Para los futuros investigadores, a la hora de aplicar AC, se debe aumentar el número de estudiantes para obtener más información y datos, lo que ayuda a demostrar que se puede mejorar la relación interpersonal y la convivencia entre todos.

- Realizar capacitaciones en donde se brinde formación interna sobre el uso de nuevos métodos del $\mathrm{AC}$, que ayude a mejorar el rendimiento académico en todas las áreas del conocimiento.

\section{DECLARACIÓN DE NO CONFLICTO DE INTERESES}

$\mathrm{Ni}$ el(los) autor(es) del artículo presentado ni su(s) familia (res) inmediata(os) tiene(tenemos) un acuerdo financiero o afiliación importante con productos y servicios empleados o abordados en el artículo o cualquier otro posible sesgo potencial en contra de otro producto o servicio. La información es propia, y los datos fueron recabados por los autores. 


\section{REFERENCIAS}

Arbildo Rojas. L., (2018) "estrategias didácticas interactivas para fomentar el estilo de aprendizaje cooperativo en los estudiantes del cuarto grado "b" de educación secundaria de la institución educativa "San Marcos", distrito pedro Gálvez, provincia San Marcos, región Cajamarca, 2016" p. 46 y 59 [ fecha de consulta 17 enero de 2021]Disponible en: http://repositorio.unprg.edu.pe/handle/UNPRG/7194

Barrios Barrios, I., Larráns Thomas, G., Sandoval López, E. (2017) El Aprendizaje Cooperativo Como Estrategia Pedagógica Para Fortalecer La Convivencia Escolar Desde Las Relaciones Ético-políticas De Las Ciencias Sociales. Disponible en: https://manglar.uninorte.edu.co/bitstream/handle/10584/7909/131342.pdf? sequence=1\&isAllowed=y

Barrios De La Ossa, J., Ortega Iglesias, J., (2010) Concepciones sobre aprendizaje cooperativo de los docentes tutores que implementan el modelo educativo flexible círculos de aprendizaje (ca) en la Región Caribe Colombiana. Disponible en: http://repositorio.unimagdalena.edu.co/jspui/handle/123456789/2166

Hernández, R. Fernández, C. y Baptista, P. (2006). Metodología de la Investigación. México: Editorial Ultra S.A. Disponible en: http://www.academia.edu/9103795/Fidias_G._Arias_El_Proyecto_de_Investigaci\%C3\%B3n_5ta._Edici $\% \mathrm{C} 3 \% \mathrm{~B} 3 \mathrm{n}$

Johnson, D. W. y Johnson, R. (1987). A meta-analysis of cooperative, competitive and individualistic goal structures. Hillsdale, N.J: Lawrence Erlbaum

Johnson, R. T., \& Johnson, D. W. y Holubec, E.J. (1994). An overview of Cooperative Learning. Baltimore, MD: Paul H.Brookes Publishing Co

Johnson, D., Jonhson, R., HOLUBEC, (1999) Los nuevos círculos del aprendizaje. La cooperación en el aula y la escuela. Buenos Aires: Aique,

Lang, R., Koegel, K., Ashbaugh, K., Regester, A., Ence, W., Smith, W. (2010). Physical exercise and individuals with autism spectrum disorders:

Marcillo Nacato, J. C. M. Nacato, Núñez Sotomayor, L. F. X.., Acuña Zapata, M. C.., \& Beltrán Vásquez, M. A... (2020). El desarrollo de los enfoques curriculares de educación física a través del aprendizaje cooperativo. Revista EDUCARE - UPEL-IPB - Segunda Nueva Etapa 2.0, 24(2), 145-166. https://doi.org/10.46498/reduipb.v24i2.1324

Ortega Ruiz, R., (1997) “La Convivencia Escolar: qué es y cómo abordarla”. Programa Educativo de Prevención de Maltrato entre compañeros y compañeras. http://educagenero.org/Recursos/convivencia_Rosario-Ortega

Orlick, T. (1978). Winning through cooperation.Washington, D.C.: Acropolis

Provost, P. \& Villeneuve, J. (1980). Jouons ensemble. Jeux et sports coopératifs. Montreal: Les editions de l'homme.

Solana, A. M. (2007). Aprendizaje cooperativo en las clases de educación física. Sevilla: Wanceulen.

Velázquez, C. (2012). El aprendizaje cooperativo en Educación Física. La formación de los grupos y su influencia en los resultados. Tándem, 39, 75-84. 
Velázquez, C. C., Fraile, A., López, P., Víctor Manuel (2014). Aprendizaje cooperativo en Educación Física. Movimiento, 20 (1), 239-259. [Fecha de Consulta 28 de agosto de 2020]. ISSN: 0104-754X. Disponible en: https://www.redalyc.org/articulo.oa?id=1153/115329361012

Zemanate Navia, N., (2017) El aprendizaje cooperativo como estrategia para dinamizar la participación escolar en el aula, en estudiantes de grado séptimo C de la institución educativa Nuestra Señora del Carmen RI: http://repositorio.unicauca.edu.co:8080/xmlui/handle/123456789/560 